\title{
Molecular and Cytogenetic Characterization of a Wheat-Rye 7BS.7RL Translocation Line with Resistance to Stripe Rust, Powdery Mildew, and Fusarium Head Blight
}

\author{
Tianheng Ren, ${ }^{1,2, \dagger}$ Zixin Sun,1,2 Zhenglong Ren,1,2 Feiquan Tan,, 1,2 Peigao Luo,1,2 Zongxiang Tang,1,2 \\ Shulan $\mathrm{Fu},{ }^{1,2}$ and $\mathrm{Zhi} \mathrm{Li}^{1,2, \dagger}$ \\ ${ }^{1}$ College of Agronomy, Sichuan Agricultural University, Wenjiang, Chengdu, Sichuan, 611130, China \\ 2 Provincial Key Laboratory for Plant Genetics and Breeding, Sichuan Agricultural University, Wenjiang, Chengdu, Sichuan, 611130, China
} Accepted for publication 26 May 2020.

\begin{abstract}
Secale cereale is used as a source of genes for disease resistance in wheat cultivation. In this study, a homozygous translocation line (RT14245) that originated from a cross between a commercial wheat cultivar (Mianyang 11) and a local Chinese variety of rye (Baili) was developed. Multicolor fluorescence in situ hybridization and PCR analysis demonstrated that the translocation chromosome was 7BS.7RL. Resistance analysis showed that RT14-245 was resistant to prevalent pathotypes of

stripe rust and powdery mildew. RT14-245 also exhibited high resistance to Fusarium head blight, which was similar to the resistance exhibited by the wheat cultivar Sumai 3 . The results indicated that RT14-245 simultaneously exhibited high levels of resistance against stripe rust, powdery mildew, and Fusarium head blight. These results indicate that chromosome arm 7RL in the translocation line RT14-245 is an excellent new resource for wheat breeding programs.
\end{abstract}

Wheat is one of the most important crops in the world, and China is one of the largest wheat-producing countries. However, three main diseases have seriously affected the production of wheat in China. Stripe rust (caused by Puccinia striiformis f. sp. tritici) is the most serious wheat disease in China. $P$. striiformis f. sp. tritici is epidemic almost every year in China, and there were violent epidemics four times, in 1950, 1964, 1990, and 2002, causing losses of 6.0 million tons, 3.2, 1.8, and 1.3 million tons of lost yield, respectively (Wan et al. 2007). In recent years, pathotypes CYR31 (239E175), CYR32 (111E239), and CYR33 (111E222) have been virulent to some newly released wheat cultivars in the field (Ren et al. 2012; Wan et al. 2004). The new emerging pathotype CYR34 (127E255) has higher frequencies, wider virulence spectrum, and is highly aggressive in China since 2010 (Huang et al. 2018) and shows virulence to almost all cultivars released in the last 20 years in Southwest China (Ren et al. 2018). Pathotypes in the "Shuiyuan" series (including SY5 and SY6) are also prevalent in China (Ren et al. 2017, 2018).

Powdery mildew (caused by Blumeria graminis f. sp. tritici) is considered to be a devastating wheat disease in China. For example, more than 12 million hectares of wheat were susceptible to powdery mildew during 1990 and 1991, causing 1.4 million tons and 0.7 million tons losses of yield, respectively (Huo et al. 2000).

†Corresponding authors: T. Ren; renth@sicau.edu.cn, and Z. Li; lizhi@sicau.edu.cn

Funding: This study was funded by National Natural Science Foundation of China (grant 31801357), and Foundation of Sichuan Province Science and Technology Support Program (grant 2019YJ0510).

First and second authors contributed equally to this work.

Author contributions: T.R. and Z.L. designed the experiment; T.R., F.T., and P.L. did the resistance analysis; Z.S., Z.T., and S.F. did the FISH; Z.L. did the molecular analysis; T.R. and Z.R. developed the translocation line; and T.R. and Z.L. wrote the paper.

The author(s) declare no conflict of interest.

(C) 2020 The American Phytopathological Society
In recent years, Fusarium head blight (caused mostly by Fusarium graminearum, FHB) has also been reported to be a frequently occurring disease. In some years, FHB epidemics could be observed and seriously affected wheat production. For example, more than 9.3 million hectares of wheat were susceptible to FHB in 2012 in China (Li et al. 2017).

The genus Secale, which includes wild and cultivated ryes, has strong potential as a source for genes desirable for wheat improvement, such as those supporting higher yields, conferring biotic and/or abiotic stress resistance, and supplying other agronomic traits (Tyrka and Chelkowski 2004). Many wheat-rye compensating Robertsonian translocations have been produced, involving essentially every rye chromosome arm, but because of structural differences between wheat and rye genomes, only a small number of those were ever accepted in breeding and spread to commercial stocks. The most famous of these translocations are the 1RS.1BL or 1RS.1AL translocations, in which the 1RS chromosome arm from rye contains many genes conferring resistance against multiple diseases and insect pests of wheat, including leaf rust ( $L r 26)$, stem rust $(\mathrm{Sr} 31)$, stripe rust $(\mathrm{Yr} 9)$, powdery mildew $(\mathrm{Pm} 8)$, green bug $(G b 2)$, and the Russian wheat aphid (Dn7) (Berzonsky et al. 1991; Friebe et al. 1996; Lapitan et al. 2007; Mago et al. 2005; Mater et al. 2004; Singh et al. 1990). In addition to disease and pest resistance, the 1RS.1BL translocation chromosome also confers higher yield and adaptive advantages to wheat in various environments (Howell et al. 2014; Kim et al. 2004). As a consequence, the 1RS.1BL and 1RS.1AL translocations have significantly impacted wheat breeding programs worldwide (Berzonsky et al. 1991; Rabinovich 1998). However, due to the narrow genetic base of 1RS (Lelley et al. 2004; Schlegel and Korzun 1997) and changes in the prevalence of virulent pathotypes, since the 1990s, resistance of the $\operatorname{Yr} 9$ and $\operatorname{Pm} 8$ genes has completely broken down in China (Ren et al. 2009). Moreover, no resistance genes against FHB were reported in rye chromatin. However, due to the higher grain and aboveground biomass yield and increased kernel weight (Howell et al. 2014; Ren et al. 2012), the 1RS.1BL translocation line still plays an important role in the wheat production program.

For further application of rye chromatin used in wheat breeding programs, other rye chromosomes besides 1RS were also introduced 
into the wheat genome. For example, the 2BS.2RL and 2AS.2RL translocations showed resistance to some diseases and pests, such as the Hessian fly, H21 (Friebe et al. 1990; Jang et al. 2003; Lee et al. 2013), leaf rust and powdery mildew (Ehdaie et al. 1998; Heun and Friebe 1990; Hysing et al. 2007). A new 2DS.2RL Robertsonian translocation transferred the stem rust resistance gene Sr59 into wheat from rye (Rahmatov et al. 2016). A line with translocations 3RS.3AL and 3RS.3BL carrying Sr27 (Marais and Marais 1994), a line with the 6BS.6RL translocation carrying Pm20 with resistance to powdery mildew, was reported (Friebe et al. 1995). However, only a small number of translocations between the rye 7R chromosome and wheat chromosome have been reported. Zeller (1981) reported wheat-rye translocations between the 4A/ 7R and 7B/4R chromosomes, and Carvalho et al. (2008) reported a spontaneous 7BS.7RL intergenomic translocation from an $F_{1}$ multigeneric hybrid. However, there have been no reports of wheat-rye 7BS.7RL translocation with resistance against stripe rust, powdery mildew and FHB.

In the present study, a novel 7BS.7RL translocation line RT14-245 was developed from a cross between common wheat 'Mianyang 11' (MY11) and a local Chinese rye 'Baili', which exhibited high levels of resistance to powdery mildew, stripe rust, and FHB. This novel 7BS.7RL translocation line could provide new resistance sources for developing improved resistant wheat cultivars.

\section{MATERIALS AND METHODS}

Plant material. A local Chinese rye variety, Baili, which was collected from southwestern China (Ren et al. 2018), was crossed as a pollen donor with a common wheat cultivar MY11. MY11 is a high-yielding wheat cultivar widely grown in southwestern China that harbors the $k r l$ gene. In the present study, the commercial wheat cultivar was used as the recipient parent to develop new wheat-rye translocation lines, employing the genetic background to the advantage of new translocation lines for practical wheat breeding. The seeds of the wheat cultivar used in the present study were produced by single seed descent from several generations to create pure genetic stocks. Since the 2000s, this cultivar has become highly susceptible to stripe rust, powdery mildew, and FHB in southwestern China.

Method to produce translocation lines. The rye and wheat was crossed from April to June, due to the flowering time, and several $C_{0}$ seeds could be obtained. To produce amphidiploids $\left(C_{1}\right)$, growing points of the $\mathrm{F}_{1}$ hybrid plants of wheat and rye were soaked in $0.05 \%$ colchicine $+3 \%$ dimethyl sulfoxide for $8 \mathrm{~h}$ and then washed overnight with running water. The $C_{1}$ plants were backcrossed twice using the same pure wheat parent, MY11, to produce $\mathrm{BC}_{2} \mathrm{~F}_{1}$ plants. $\mathrm{BC}_{2} \mathrm{~F}_{2}$ was reproduced by selfing. The $\mathrm{BC}_{2} \mathrm{~F}_{1}$ and $\mathrm{BC}_{2} \mathrm{~F}_{2}$ seedling plants were cultured in the lab first, the root tips were collected and used for multicolor fluorescence in situ hybridization (MC-FISH) examination, and then the plants were grown in the field. Using this method, we were able to clearly determine the chromosome constitution for each plant.

In the $\mathrm{BC}_{2} \mathrm{~F}_{1}$ and $\mathrm{BC}_{2} \mathrm{~F}_{2}$ generations, we could obtain many different kinds of monosomic addition lines. Several wheat/rye monosomic addition (MA) plants or double monosomic addition (DMA, with two different monosomic chromosomes) plants could be selected by MC-FISH in these two generations, which had an intact genetic background of wheat and different addition rye chromosomes. Several plants also exhibited high resistance to diseases in the field. Only the MA or DMA plants that showed resistance were sequentially chosen and reproduced to obtain the next generation. The seeds of these new monosomic addition plants were harvested. Currently, only plants that exhibit high resistance to diseases are harvested and reproduced by selfing. From $\mathrm{BC}_{2} \mathrm{~F}_{5}$, the seedling plants could be identified by MC-FISH again and then grown in the field. This work could be continued until we obtained homozygous translocation, substitution, or addition plants.
For each generation that requires MC-FISH examination, we usually detect 20 to 30 seeds. If we found the homozygotes, the detected experiments would be stopped, and the seeds of these homozygotes would be harvested. However, if we did not find the homozygote, FISH would be continued until we obtained at least one homozygote. Sometimes, unfortunately, we did not find any homozygotes after we detected all the seeds. In this situation, the heterozygotes would be planted, and the homozygotes would be detected in the next generation.

Chromosome identification. FISH and genomic in situ hybridization (GISH) were used to analyze the mitotic metaphase cells of the materials used in this study according to Fu et al. (2014) and Ren et al. (2017). In our lab, FISH and GISH were used together in one hybridization, but the probes were labeled by different colors; therefore, we also named them MC-FISH (Ren et al. 2017). The genomic DNA of Baili rye, Aegilops tauschii clone pAs1, and rye clone $\mathrm{pSc} 119.2$ were used together in the same slide as probes to distinguish between wheat, rye and translocation chromosomes in this study. The genomic DNA of Baili rye and the repetitive sequences of pAs1 were labeled with Texas red-5-dUTP (Invitrogen) (red). The repetitive sequences of pSc119.2 were labeled with Alexa Fluor-488-5-dUTP (Invitrogen) (green). Probe labeling was conducted as described by Fu et al. (2014) and Ren et al. (2017). Images were captured using an epifluorescence microscope (BX51, Olympus) equipped with a cooled charge-coupled device camera and operated with HCIMAGE Live software (version 2.0.1.5).

PCR analysis. Total genomic DNA of plant materials was isolated from young leaves by the surfactant cetyltrimethylammonium bromide (Doyle and Doyle 1987). The RT14-245 seeds used in this experiment were collected from three different generations. The wheat and rye parents were used as controls.

A codominant PCR-based landmark unique gene (PLUG) marker TNAC1811 (5'-CTGCTCAACGAGTTCATCGAC-3'; 5'-TTGGAGTG GACGTTGCATT-3'), which was specific for the rye 7RL chromosome arm ( $\mathrm{Li}$ et al. 2013), and a simple-sequence repeat (SSR) marker xwmc526 (5'-TCCCATTGGTTCACAAACTCG3'; 5'-GATGGTATCGCATTCATCGGT-3'), which was specific for the wheat 7BL chromosome arm (Wang et al. 2009), were used to confirm that the 7BL chromosome arm was replaced by the 7RL chromosome arm in RT14-245.

PCR was carried out in a Bio-Rad iCycler thermal cycler (BioRad Laboratories, Inc., Hercules, CA). DNA was amplified with a $0.5 \mathrm{U}$ of Taq DNA polymerase enzyme, $1 \times$ buffer, $1.5 \mathrm{mM} \mathrm{MgCl}_{2}$, $200 \mathrm{mM}$ dNTPs, $10 \mathrm{mmol}$ primer, and $50 \mathrm{ng}$ of DNA in a total volume of $25 \mathrm{ml}$. After initial denaturation for $4 \mathrm{~min}$ at $94^{\circ} \mathrm{C}$, each cycle included $60 \mathrm{~s}$ of denaturation at $94^{\circ} \mathrm{C}, 60 \mathrm{~s}$ of annealing at $58^{\circ} \mathrm{C}(\mathrm{TNAC} 1811) / 60^{\circ} \mathrm{C}(\mathrm{xwmc} 526)$, and $1 \mathrm{~min}$ of extension at $72^{\circ} \mathrm{C}$. A final extension for $10 \mathrm{~min}$ at $72^{\circ} \mathrm{C}$ followed the 30 cycles. PCR products were analyzed by electrophoresis on $1 \%$ agarose gels stained with ethidium bromide or $8 \%$ (wt/vol) nondenaturing polyacrylamide gels stained with $\mathrm{AgNO}_{3}$.

Phenotypic analysis. All plant materials in the present study were examined for resistance to stripe rust and powdery mildew in the greenhouse during the seedling stage using the methods described by Ren et al. (2012), Wan et al. (2004), and Wang et al. (2005). Six $P$. striiformis f. sp. tritici pathotypes were used in this experiment: CYR31 (virulent to $\mathrm{Yrl}, 2,3,6,7,9,27, \mathrm{~A}, \mathrm{Alba}$, Cle, $C V, G a b y, \operatorname{Res}, S D$, and $S O$ ), CYR32 (virulent to $\operatorname{Yrl} 1,2,3,4,6,9,27$, A, Alba, Cle, CV, Gaby, Res, SD, SO, SpP), CYR33 (virulent to Yr1, $2,3,4,6,7,8,9,11,12,17,18,25,28,29,30,31,32, A$, and $S u$ ), and CYR34 (virulent to $\operatorname{Yrl} 1,2,3,4,6,7,8,9,10,17,18,24,26,27,29$, $32, S p, A$, and $S k$ ). SY 5 and SY6 have been virulent to many released wheat cultivars in China in recent decades and are also virulent to Yr9. These six P. striiformis f. sp. tritici pathotypes were considered to have the highest frequency and virulence in southwestern China. All P. striiformis f. sp. tritici pathotypes were provided by the Plant Protection Institute, Gansu Academy of Agricultural Sciences, China. The wheat parent MY11, rye parent Baili, and 1RS.1BL 
translocation line Chuan-Nong 10 (CN10, containing the $\mathrm{Yr} 9$ gene) were used as controls. Infection types (IT) were scored based on the 0 to 9 scale for stripe rust: IT 0 to 3 are considered to be resistant to stripe rust, IT 4 to 6 are intermediate for resistance to stripe rust, and IT 7 to 9 are susceptible to stripe rust.

B. graminis f. sp. tritici isolates No. 9 and No. 15, which show severe virulence to many cultivars released in the last 20 years in Southwest China and virulence to $P m 8$ and $P m 17$, were provided by the Provincial Key Laboratory for Plant Genetics and Breeding of Sichuan Agricultural University. A 0 to 4 IT scale was used to record the host response to powdery mildew infection according to Wang et al. (2005).

All plant materials were examined for resistance in the field without artificial inoculation at Qionglai Research Station of Sichuan Agricultural University in Southwest China $\left(30^{\circ} 25^{\prime} \mathrm{N}\right.$, $103^{\circ} 28^{\prime} \mathrm{E}$, at $493.3 \mathrm{~m}$ above sea level) from 2015 to 2018 , where the climate is temperate and rainy with a serious prevalence of stripe rust and powdery mildew. Entries were arranged in a randomized, complete block design with three replicates. The plots consisted of six rows with $3 \mathrm{~m}$ long, $25 \mathrm{~cm}$ row spacing, and $0.1 \mathrm{~m}$ of plant space. All plants were naturally infected during the heading to flowering period, and disease reactions were scored at the heading stage for powdery mildew and at the grain filling stage for stripe rust. Wheat cultivars MY11 and CN10 were used as controls.

The plant materials were also examined for resistance to FHB in the greenhouse according to the method described by $\mathrm{Li}$ et al. (2017). Five microliters of a macroconidial suspension (200 macroconidia/ $\mu l$ ) of an isolate of $F$. graminearum was injected into two opposite florets in a spikelet at early anthesis. The isolate originated from wheat heads with heavy scab symptoms collected from a field at Ya-an, Sichuan. Thirty main spikes of each control and translocation line entry were selected for inoculation and were covered with plastic bags for 3 days to maintain the relative humidity. The percentage of diseased spikelets (PDS), including the inoculated spikelets, was recorded at 21 days after inoculation. Spikes inoculated with the $F$. graminearum isolate and control spikes were harvested and threshed manually. The percentage of damaged kernels (PDK) was calculated. Wheat cultivar Sumai 3 was used as a control. The cultivar Sumai 3 is widely recognized as highly resistant to FHB (Li et al. 2017).

\section{RESULTS}

Development and molecular cytogenetic identification of the 7BS.7RL translocation line. The pedigree of RT14-245 is displayed in Figure 1.

Using the MC-FISH technique, wheat and rye chromosomes are easily distinguished in wheat-rye hybrid offspring plants. Every arm of the $7 \mathrm{~B}$ and $7 \mathrm{R}$ chromosomes shows specific signals for identification (Fig. 2A and B). The wheat cultivar MY11 was easily crossed with the rye variety Baili. No rye chromatin was detected in this cultivar based on FISH techniques (Fig. 2A). The amphidiploid plants $\left(\mathrm{C}_{1}\right)$ were backcrossed twice with the wheat parent MY11. Several 1R to 7R addition plants were obtained from $\mathrm{BC}_{2} \mathrm{~F}_{1}$ generations. In this experiment, from the $\mathrm{BC}_{2} \mathrm{~F}_{1}$ population, one plant with monosomic addition of $7 \mathrm{R}$ chromosome $(2 \mathrm{n}=43=$ 21 ' $\mathrm{W}+1$ '7R) was selected (Fig. 2C), which exhibited high levels of resistance to strip rust and powdery mildew (Fig. 1, Table 1). These $7 \mathrm{R}$ monosomic addition plants were harvested and reproduced as the next generation $\left(\mathrm{BC}_{2} \mathrm{~F}_{2}\right)$ in an isolation field by selfing. The seeds of the progeny of this $7 \mathrm{R}$ monosomic addition plant were cultured in the lab for one week, and then the root tips of plants were collected and used for chromosomes identified by MC-FISH. Then, all plants were grown in the field. Only the plants that showed resistance to diseases were harvested. In this generation, several 7R chromosomes were broken and randomly assigned to offspring plants. The FISH results and resistance analysis indicated that all the plants $(2 n=44=42 \mathrm{~W}+1$ " $7 \mathrm{RL})$ with a pair of long arms of $7 \mathrm{R}$ (Fig. 2D) still exhibited resistance to strip rust and powdery mildew (Table 1). However, all the plants did not contain $7 \mathrm{R}(2 \mathrm{n}=42=$ 21 'W) or only contained 7RS $(2 \mathrm{n}=44=21$ "W +1 " $7 \mathrm{RS})$ chromosomes and were susceptible to strip rust and powdery mildew (Fig. 1, Table 1). The results indicated that the genes controlling resistance to strip rust and powdery mildew were located on the long arm of the 7R chromosome. The plants with a pair of long arms of $7 \mathrm{R}$ were harvested and reproduced by selfing to obtain the next generation. From $\mathrm{BC}_{2} \mathrm{~F}_{3}$ to $\mathrm{BC}_{2} \mathrm{~F}_{4}$, only the plants with resistance would be harvested and reproduced. In the $\mathrm{BC}_{2} \mathrm{~F}_{5}$ generation, 20 seeds were identified by MC-FISH before sowing, and one plant containing a pair of 7BS.7RL translocation chromosomes (Fig. 2E and F) was selected. This plant was carefully planted in the experimental field and exhibited high resistance to stripe rust and powdery mildew. The progenies of this plant showed consistent morphological characteristics. The seeds of the continued three generations were identified by MC-FISH and indicated that the 7BS.7RL translocation chromosomes could be inherited normally. These results indicate that it is a stable homozygous line, which was named RT14-245 $(2 \mathrm{n}=42)$.

To confirm the presence of 7RL and absence of 7BL in line RT14235, the PLUG marker TNAC1811, which was specific for rye 7RL, and the SSR marker Xwmc526, which was specific for wheat 7BL, were used. All the plants from translocation line RT14-245 showed specific PCR amplification with the marker TNAC1811 (Fig. 3A), while they did not show specific PCR amplification with the marker Xwmc526 (Fig. 3B). This result indicated that in RT14245 , the wheat $7 \mathrm{BL}$ chromosome arms were replaced by rye $7 \mathrm{RL}$ chromosome arms.

Analysis for resistance to stripe rust. Plant materials were examined for resistance to stripe rust by six P. striiformis $\mathrm{f}$. sp. tritici pathotypes (CYR31, CYR32, CYR33, CYR34, SY5, and SY6) in the greenhouse during the seedling stage. The wheat parent MY11 was highly susceptible to the six $P$. striiformis $\mathrm{f}$. sp. tritici pathotypes. On the other hand, Baili rye exhibited high levels of resistance to six $P$. striiformis f. sp. tritici pathotypes (Table 2). Wheat cultivar CN10 (control), which inherited the 1RS.1BL chromosome from the Russian wheat cultivar Aurora (carrying $\operatorname{Yr} 9$ ), was highly susceptible to five $P$. striiformis $\mathrm{f}$. $\mathrm{sp}$. tritici pathotypes (CYR31, CYR32, CYR33, CYR34, and SY6) but exhibited resistance to SY5 (Table 2). The 7RL.7BS translocation line RT14-245 exhibited high resistance against six inoculating pathotypes of stripe rust (Table 2).

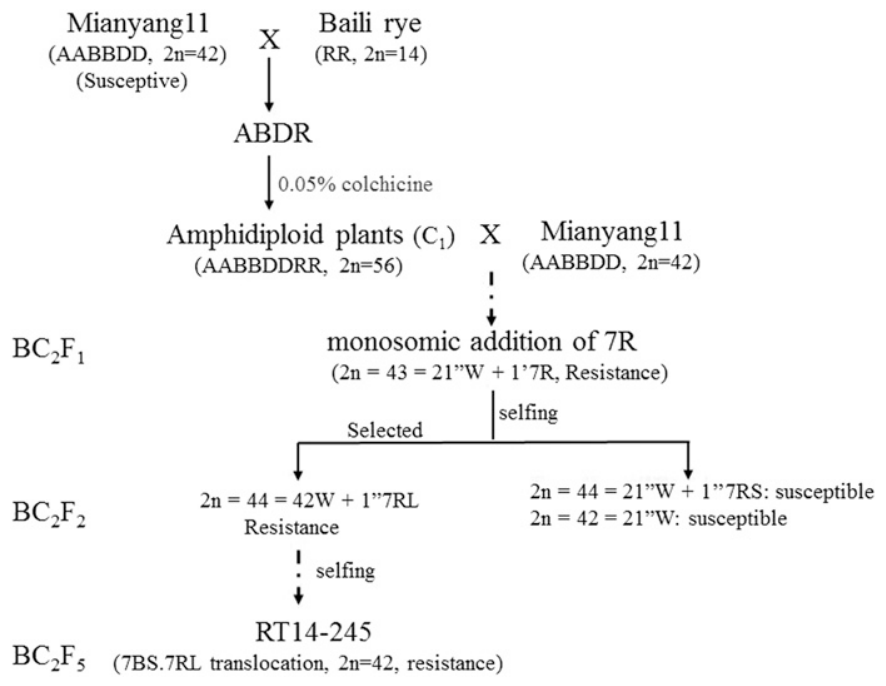

Fig. 1. The pedigree of RT14-245. 
In the field experiments, the wheat cultivars MY11 and CN10 showed severe susceptibility to stripe rust during the filling stage. On the other hand, translocation line RT14-245 exhibited high resistance against stripe rust in the field at the same time (Fig. 4A).
The results indicated that translocation line RT14-245 exhibited all-stage resistance to stripe rust (Table 2).

Analysis for resistance to powdery mildew. Plant materials were examined for resistance to powdery mildew by two $B$. graminis f. sp. tritici isolates (No. 9 and No. 15) in the greenhouse during the
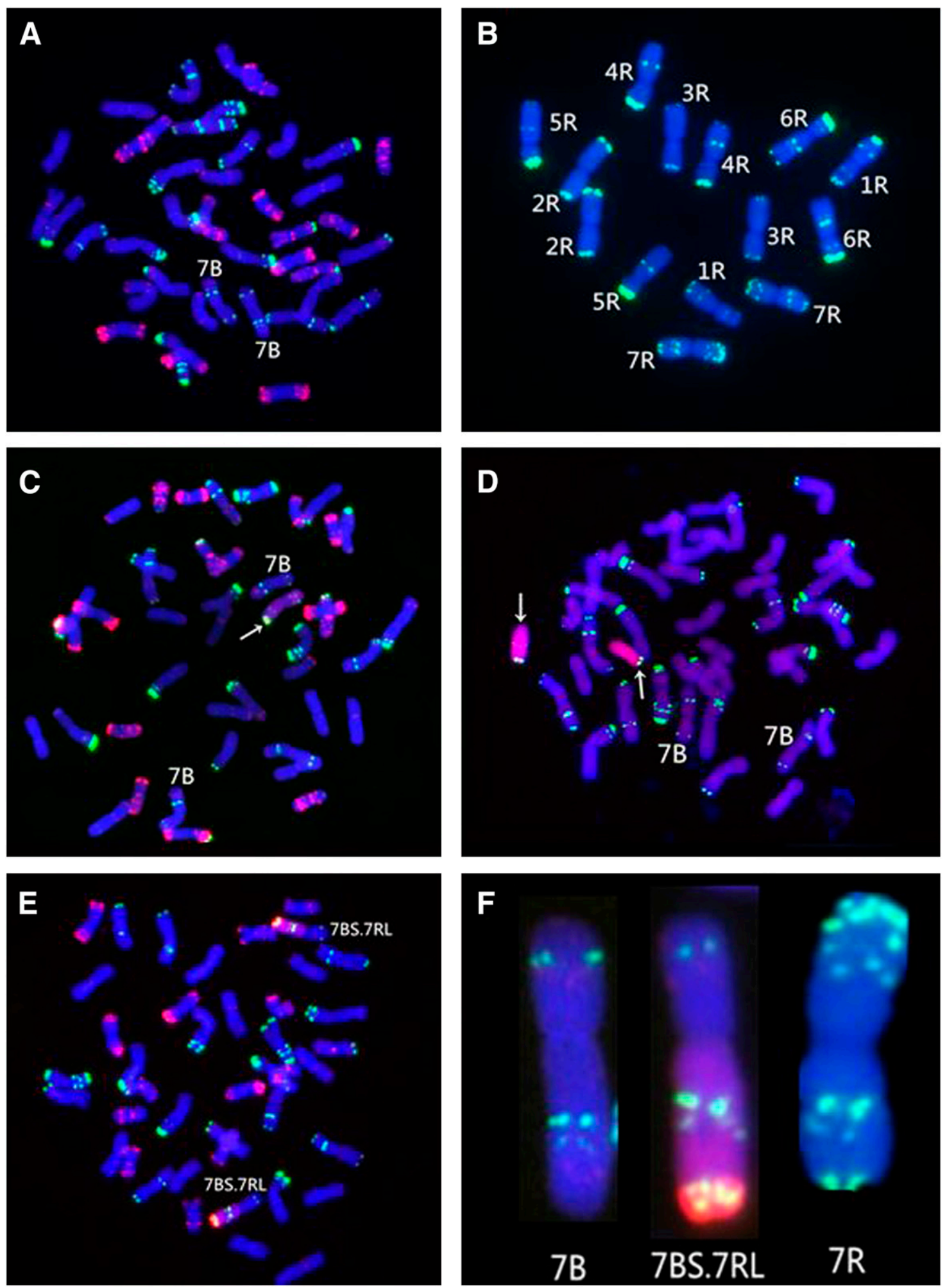

Fig. 2. Molecular cytogenetic identification of wheat-rye translocation 7BS.7RL. A, Wheat parent, each arm of chromosome 7B is easily distinguished using pSc119.2 and pAs1 as probes. B, Rye parent, each arm of chromosome 7R is easily distinguished using pSc119.2 as a probe. C, The 7R monosomic addition line, $2 \mathrm{n}=43$. The arrow indicated the $7 \mathrm{R}$ chromosome. D, A plant from hybrid progenies with a pair of $7 \mathrm{RL}$ arms, $2 \mathrm{n}=42 \mathrm{~W}+1$ " $7 \mathrm{RL}$. The arrow indicated the $7 \mathrm{RL}$ chromosome arms. E, The chromosomes of a homozygous 7BS.7RL translocation line. F, Comparison among chromosomes 7B, 7R, and 7BS.7RL. Rye genomic DNA (red), pSc119.2 (green), and pAs1 (red). 
seedling stage. The wheat parent MY11 and wheat cultivar CN10 (control, carrying $P m 8$ ) were highly susceptible to both $B$. graminis f. sp. tritici isolates, whereas Baili rye and the 7BS.7RL translocation line RT14-245 exhibited high resistance against both inoculating isolates of powdery mildew (Table 3 ).

Field experiments were also conducted for powdery mildew resistance analysis. MY11 and CN10 showed very severe symptoms of powdery mildew in the field during the heading stage, but the 7BS.7RL translocation line RT14-245 showed high resistance to powdery mildew in the field during the heading stage (Table 3, Fig. 4B).

These results indicated that the translocation line RT14-245 exhibited all-stage resistance to powdery mildew.

Analysis for resistance to FHB. In 2015, FHB epidemics occurred severely in the field of southwestern China. The wheat parent MY11 was infected and showed serious FHB symptoms. The 7BS.7RL translocation line RT14-245 translocation line was planted next to MY11 under the same field conditions and disease pressure but showed resistance to FHB (Fig. 4C). Did this phenomenon suggest RT14-245 also has resistance ability to FHB? Therefore, an experiment for FHB resistance analysis of RT14-245 was carried out in the greenhouse.

The wheat parent MY11 was infected with FHB and showed severe symptoms of FHB, and the PDS and PDK of MY11 were calculated to be 64.28 and $47.87 \%$, respectively. However, the PDS and PDK of RT14-245 were only calculated to be 8.85 and $11.46 \%$, respectively. The PDS and PDK of the FHB resistance control cultivar Sumai 3 were calculated to be 10.86 and $12.27 \%$, respectively. The results showed that there was a significant increase in FHB resistance between translocation line RT14-245 and its wheat parent MY11, and the degree of resistance to FHB in RT14-245 was similar to that of the wheat cultivar Sumai 3 (Table 4).

This result indicated that translocation line RT14-245 showed high resistance to FHB.

\section{DISCUSSION}

Development and identification of wheat-rye translocation 7BS.7RL. Rye (Secale cereale L.) has strong potential as a gene source for wheat improvement (Tyrka and Chelkowski 2004). Many useful genes of rye, including genes for resistance to diseases and agronomic traits, have been transferred into wheat through the creation of chromosome translocations (Friebe et al. 1996; MolnárLáng et al. 2014; Qi et al. 2007). These wheat-rye translocation lines, especially $1 \mathrm{RS} .1 \mathrm{BL}$ translocations, are highly important genetic resources for wheat breeding programs and are widely used in wheat breeding programs worldwide. However, wheat-rye translocation involving the $7 \mathrm{R}$ chromosome of rye has rarely been reported.

There were several ways to develop alien translocation chromosomes (Lukaszewski and Gustafson 1983; Molnár-Láng et al. 2010; Riley et al. 1968; Sears 1972). In our previous study, we found a more efficient method to develop wheat-rye translocations (Ren et al. 1990). Many Chinese commercial wheat cultivars (such as MY11) have cross ability genes $k r l$ or $k r 2$, and they can be crossed with rye directly (Ren et al. 2009). The hybrid $F_{1}$ was treated with colchicine and backcrossed with the same wheat parent. The MA plants were easily obtained from the progeny after two backcrosses (Zhang and Ren 1998). Among the progeny of MA plants, at least onethird of plants retained the additional alien chromosomes (Zhang and Ren 1998). Therefore, once the MA plants were successfully selected, they could be used as durable sources of chromosome transfer. Hundreds of novel translocations were obtained in the past two decades by this method in our lab. However, few of the translocations exhibited high resistance to diseases, and most of the new translocations with resistance were still 1RS.1BL translocations (Ren et al. 2009, 2012, 2017, 2018).

In the present study, a new form of Robertsonian translocation between wheat and rye homologous chromosomes, 7BS.7RL, is reported, which originated from a commercial wheat cultivar and a local Chinese variety of rye. Using the MC-FISH technique, specific molecular signals were associated with the arms of $7 \mathrm{~B}$ and $7 \mathrm{R}$ chromosomes; therefore, the translocation chromosome 7BS.7RL was easily distinguished under a microscope (Fig. 2). Recently, Li et al. (2013) developed a set of rye-specific PLUG markers as an effective tool for recognizing different chromosome arms of rye. In the present study, to confirm 7BS.7RL in the translocation line RT14-245, a rye-specific PLUG marker of arm 7RL TNAC1811 and a wheat-specific SSR marker of arm 7BL xwmc526 were used. All plants from the translocation line RT14245 showed specific signals of PCR amplification with the marker TNAC1811 and the absence of the signals of PCR amplification with the marker xwmc526 (Fig. 3), which indicated that the translocation chromosome involved in the translocation line RT14245 was the 7BS.7RL arm.

Resistance of translocation line RT14-245 to multiple diseases in wheat. Based on ecological conditions, wheat stripe rust in China can be divided into three major zones, namely, the autumn sources of inocula, the spring sources of inocula, and spring epidemic areas (Chen et al. 2013). In Sichuan Province, stripe rust cannot oversummer but continually increases in winter, and it is the spring inoculum source of stripe rust. Sichuan Province is the key management area to reduce the intensity of stripe rust in China (Chen et al. 2013). The cultivation of resistant wheat cultivars has been the most environmentally friendly and effective strategy for controlling disease. Unfortunately, since the 1990 s, many resistance genes for stripe rust and powdery mildew that are frequently used in

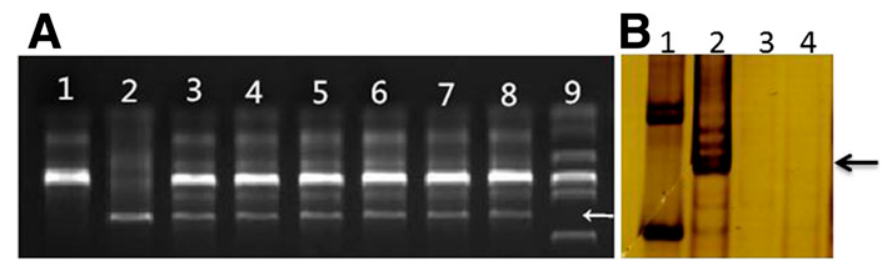

Fig. 3. PCR results of rye 7RL specific marker TNAC1811 and wheat 7BL specific marker xwmc526 (indicated with arrow). A, PCR results of TNAC1811. From left to right: lane 1, wheat parent Mianyang 11 (MY11); lane 2, rye parent Baili; lanes 3 to 8, different plants from line RT14-245; and lane 9, marker D2000. B, PCR results of xwmc526. From left to right: lane 1, marker D2000; lane 2, wheat parent MY11; and lanes 3 to 4, different plants from line RT14-245.

TABLE 1. Resistance ability of different plants with different chromosome formation ${ }^{\mathrm{z}}$

\begin{tabular}{|c|c|c|c|}
\hline Line & Chromosome structure & Response to stripe rust & Response to powdery mildew \\
\hline Mianyang 11 (MY11, wheat parent) & $2 \mathrm{n}=42=21 \mathrm{~W}$ & $\mathrm{~S}$ & $\mathrm{~S}$ \\
\hline RT14-245 (T7BS.7RL) & $2 \mathrm{n}=42=20 \mathrm{~W} "+7 \mathrm{BS} .7 \mathrm{RL} "$ & $\mathrm{R}$ & $\mathrm{R}$ \\
\hline $7 \mathrm{R}$ monosomic addition line & $2 n=43=21 W^{\prime \prime}+7 R^{\prime}$ & $\mathrm{R}$ & $\mathrm{R}$ \\
\hline 7RL disomic addition line & $2 \mathrm{n}=44=21 \mathrm{~W} "+7 \mathrm{RL} "$ & $\mathrm{R}$ & $\mathrm{R}$ \\
\hline 7RS disomic addition line & $2 \mathrm{n}=44=21 \mathrm{~W} "+7 \mathrm{RS} "$ & $\mathrm{~S}$ & $\mathrm{~S}$ \\
\hline
\end{tabular}

z $\mathrm{S}$, susceptible; $\mathrm{R}$, resistance. 
wheat breeding programs in Southwest China have lost their resistance due to the prevalence of new virulent pathogens (Ren et al. 2017). FHB resistance in wheat is polygenic and seven FHB resistance quantitative trait loci (QTLs) have been reported to date (Li et al. 2017). However, only a small number of FHB resistance QTLs have been successfully used in wheat breeding programs because of weak resistance, poor adaptation, and the complex genetic backgrounds of some QTLs. Globally, wheat breeding for resistance to FHB relies heavily on the Chinese cultivar Sumai 3 and its derivatives (Rudd et al. 2001). Therefore, the search for new genetic resources of resistance to stripe rust, powdery mildew, and FHB is critical.

Robertsonian translocation that involves two intact arms of alien and wheat chromosomes is an effective method to transfer alien genes into wheat (Friebe et al. 1996; Molnár-Láng et al. 2014; Qi et al. 2007). Several chromosome arms of rye with important genes for resistance to diseases and pests have been introduced into wheat through Robertsonian translocations between homologous wheat-rye chromosomes, including the genes $\operatorname{Lr} 26, \mathrm{Sr} 31$, $\operatorname{Yr}$ 9, $\mathrm{YrCN17}, \mathrm{Pm} 8, \mathrm{PmCN17}, \mathrm{Gb2}$, and $\mathrm{Dn} 7 \mathrm{on}$ chromosome 1RS (Friebe et al. 1996; Lapitan et al. 2007; Mago et al. 2005; Ren et al. 2009); H21 and Sr59 on chromosome 2RL (Heun and Friebe 1990; Lee et al. 2013; Rahmatov et al. 2016); Sr27 on chromosome 3RS (Marais and Marais 1994); and Pm20 on chromosome 6RL (Friebe et al. 1995; Heun and Friebe 1990). In the present study, a new translocation line, RT14-245, was reported to carry a pair of 7BS.7RL chromosomes. This novel primary 7BS.7RL translocation line inherited its 7RL chromosome arm from the Chinese rye Baili and exhibited high resistance to stripe rust and powdery mildew (Tables 1,2, and 3). However, the wheat parent line, MY11, was highly susceptible to all isolates used in this study and was susceptible in the open field (Tables 1, 2, and 3). During the development process, the 7R or 7RL addition lines were resistant to diseases, but the progenies that lost 7R or 7RL of these addition lines were susceptible again (Fig. 1, Table 1). These findings suggested that the origin of the resistance was through the introduction of the 7RL chromosome. These results demonstrate that new resistance genes against $P$. striiformis f. sp. tritici and B. graminis f. sp. tritici in novel translocation lines should be located on the 7RL chromosome, which originated from Baili rye.

The translocation line also showed significantly better resistance to FHB than that of the wheat parent, MY11 (Table 4). Because translocation line RT14-245 possessed the pure genetic background of wheat cultivar MY11 and a pair of introduced 7RL chromosome arms, a reasonable deduction is that the $7 \mathrm{RL}$ chromosome arm carried new gene(s) for resistance to FHB. The resistance of the translocation line RT14-245 to FHB was similar to that of Sumai 3, a wheat germplasm known for FHB resistance (Table 4). The general consensus is that the FHB resistance of wheat cultivar Sumai 3 is controlled by a polygenic system. Because the difference between translocation line RT14-245 and its wheat parent could occur only by the substitution of the 7BL chromosome with the 7RL chromosome, translocation line RT14-245 is expected to be a

TABLE 3. Responses to different powdery mildew (Blumeria graminis f. sp. tritici) isolates in the 7BS.7RL translocation line originating from wheat cultivar Mianyang 11 (MY11) and rye variety Bailiz

\begin{tabular}{lcccc}
\hline & & \multicolumn{2}{c}{$\begin{array}{c}\text { B. graminis f. sp. tritici } \\
\text { isolates }\end{array}$} \\
\cline { 2 - 5 } $\begin{array}{l}\text { Translocation line and } \\
\text { controls }\end{array}$ & $\begin{array}{c}\text { Chromosome } \\
\text { type }\end{array}$ & No. 9 & No. 15 & In field \\
\hline RT14-245 & 7BS.7RL & 0 & 1 & 1 \\
MY11 & 7B & 4 & 4 & 4 \\
Baili & 7R & 0 & 0 & 0 \\
CN10 (control) & 1RS.1BL & 4 & 4 & 4 \\
\hline
\end{tabular}

z No visible symptoms (infection type [IT] 0), hypersensitive necrotic flecks (IT 0;), minute colonies with few conidia produced (IT 1), colonies with moderately developed hyphae, but few conidia (IT 2), colonies with welldeveloped hyphae and abundant conidia, but colonies not joined together (IT 3 ), and colonies with well-developed hyphae and abundant conidia, and colonies mostly joined together (IT 4).

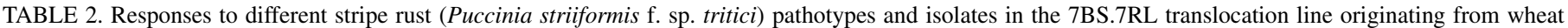
cultivar Mianyang 11 (MY11) and rye cultivar Bailiz

\begin{tabular}{|c|c|c|c|c|c|c|c|c|}
\hline \multirow[b]{2}{*}{ Translocation line and controls } & \multirow[b]{2}{*}{ Chromosome type } & \multicolumn{6}{|c|}{ P. striiformis $\mathrm{f}$. sp. tritici pathotypes and isolates } & \multirow[b]{2}{*}{ In field } \\
\hline & & CYR31 & CYR32 & CYR33 & CYR34 & SY5 & SY6 & \\
\hline RT14-245 & 7BS.7RL & 0 & 0 & 0 & 0 & 0 & 0 & 1 \\
\hline MY11 & $7 \mathrm{~B}$ & 8 & 8 & 8 & 8 & 8 & 8 & 9 \\
\hline Baili & $7 \mathrm{R}$ & 0 & 0 & 0 & 0 & 0 & 0 & 0 \\
\hline CN10 (control) & 1RS.1BL & 6 & 6 & 8 & 8 & 0 & 0 & 9 \\
\hline
\end{tabular}

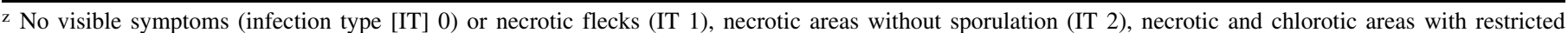
sporulation (IT 3), or moderate uredinia with necrosis and chlorosis (IT 4 to 6), abundant uredia with chlorosis (IT 7 to 8 ) and without chlorosis (IT 9).
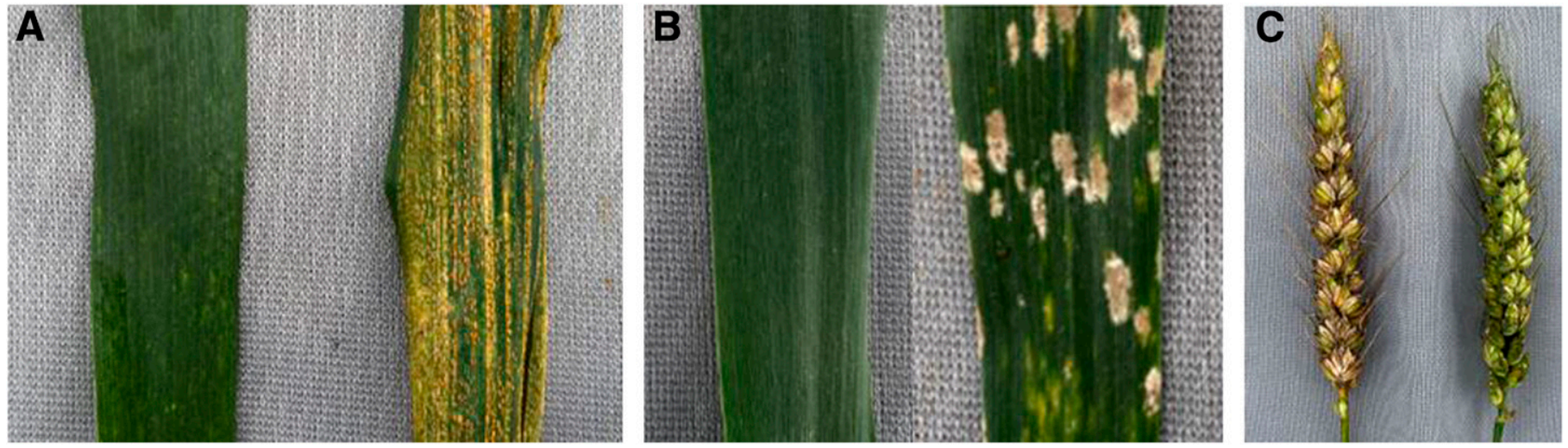

Fig. 4. Resistance of translocation line RT14-245 to multiple diseases in the field. A, Resistance to stripe rust: left, RT14-245; and right, Mianyang 11 (MY11). B, Resistance to powdery mildew: left, RT14-245; and right, CN10. C, Resistance to Fusarium head blight: left, MY11; and right, RT14-245. The plants were grown in the field and natural infected. 
TABLE 4. Means of the percentage of diseased spikelets (PDS) and percentage of damaged kernels (PDK) as measures of resistance to Fusarium head blight in the wheat parent and translocation line RT14-245z

\begin{tabular}{lcrc}
\hline Translocation line and controls & Chromosome type & PDS (\%) & PDK (\%) \\
\hline RT14-245 & 7BS.7RL & $8.85 \mathrm{~b}$ & $11.46 \mathrm{~b}$ \\
Mianyang 11 (MY11) & $7 \mathrm{~B}$ & $64.28 \mathrm{a}$ & $47.87 \mathrm{a}$ \\
Sumai 3 & 7B & $10.86 \mathrm{~b}$ & $12.27 \mathrm{~b}$
\end{tabular}

$\mathrm{z}$ Analysis of variance was performed on the collected data for each resistance parameter. Least significant differences were calculated for mean comparisons. Values followed by the same letter in the same column are not significantly different at $P<0.05$.

better germplasm for resistance to FHB in wheat breeding programs.

Conclusion. The most famous example of the application of alien translocation in wheat improvement is the 1RS.1BL translocation, in which the $1 \mathrm{RS}$ arm from rye contains numerous resistance genes against multiple diseases and pests (Lapitan et al. 2007; Mago et al. 2005; Rabinovich 1998). In the present study, a new wheat-rye translocation RT14-245 was developed by the cross between rye 'Baili' and wheat 'MY11'. This new germplasm RT14245 with the translocation chromosome 7BS.7RL showed resistance against multiple wheat diseases (Tables 2, 3, and 4), providing new resistance sources for developing improved resistant wheat cultivars.

\section{LITERATURE CITED}

Berzonsky, W. A., Clements, R. L., and Lafever, H. N. 1991. Identification of 'Amigo' and 'Kavkaz' translocations in Ohio soft red winter wheats (Triticum aestivum L.). Theor. Appl. Genet. 81:629-634.

Carvalho, A., Martín, A., Heslop-Harrison, P., Guedes-Pinto, H., and Lima-Brito, J. 2008. Identification of the spontaneous 7BS/7RL intergenomic translocation in one $F_{1}$ multigeneric hybrid from the Triticeae tribe. Plant Breed. 128:105-108.

Chen, W., Kang, Z., Ma, Z., Xu, S., Jin, S., and Jiang, Y. 2013. Integrated management of wheat stripe rust caused by Puccinia striiformis f. sp. tritici in China. Sci. Agric. Sin. 46:4254-4262.

Doyle, J. J., and Doyle, J. L. 1987. A rapid DNA isolation procedure from small quantities of fresh leaf tissues. Phytochem. Bull. 19:11-15.

Ehdaie, B., Barnhart, D., and Waines, J. G. 1998. Effects of the 2AS.2RL translocation on grain yield and evapotranspiration efficiency of "Chinese Spring" bread wheat. Pages 2-7 in: Proc. Int. 9th Wheat Genet. Symp. Vol. 2. A. E. Slinkard, ed. Canada.

Friebe, B., Gill, B. S., Tuleen, N. A., and Cox, T. S. 1995. Registration of KS93WGRC28 powdery mildew resistant T6BS.6RL wheat germplasm. Crop Sci. 35:1237.

Friebe, B., Hatchett, J. H., Sears, R. G., and Gill, B. S. 1990. Transfer of Hessian fly resistance from 'Chaupon' rye to hexaploid wheat via a $2 \mathrm{BS} /$ 2RL wheat-rye chromosome translocation. Theor. Appl. Genet. 79:385-389.

Friebe, B., Jiang, J., Raupp, W. J., McIntosh, R. A., and Gill, B. S. 1996. Characterization of wheat-alien translocations conferring resistance to disease and pests: Current status. Euphytica 91:59-87.

Fu, S. L., Ren, Z. L., Chen, X. M., Yan, B. J., Tan, F. Q., Fu, T. H., and Tang, Z. X. 2014. New wheat-rye 5DS-4RS.4RL and 4RS-5DS.5DL translocation lines with powdery mildew resistance. J. Plant Res. 127:743-753.

Heun, M., and Friebe, B. 1990. Introgression of powdery mildew resistance from rye into wheat. Phytopathology 80:242-245.

Howell, T., Hale, I., Jankuloski, L., Bonafede, M., Gilbert, M., and Dubcovsky, J. 2014. Mapping a region within the 1RS.1BL translocation in common wheat affecting grain yield and canopy water status. Theor. Appl. Genet. 127:2695-2709.

Huang, J., Jia, Q., Zhang, B., Sun, Z., Huang, M., and Jin, S. 2018. Epidemic forecasting of the new strains G22-9 (CYR34) and G22-14 of Puccinia striiformis f. sp. tritici in wheat in Gansu Province. J. Plant Prot. 45:101-108.

Huo, Z. G., Liu, W. C., Shao, Z. R., and Jiang, R. Z. 2000. On developing long-term meteorological prediction research of crops pests and diseases prevailing in China. J. Nat. Disasters 9:117-121.

Hysing, S. C., Hsam, S. L. K., Singh, R. P., Huerta-Espino, J., Boyd, L. A., Koebner, R. M. D., Cambron, S., Johnson, J. W., Bland, D. E., and Liljeroth, E. 2007. Agronomic performance and multiple disease resistance in T2BS.2RL wheat-rye translocation lines. Crop Sci. 47:254-260.
Jang, C. S., Kim, J. Y., Haam, J. W., Lee, M. S., Kim, D. S., Li, Y. W., and Seo, Y. W. 2003. Expressed sequence tags from a wheat-rye translocation line (2BS/2RL) infested by larvae of Hessian fly [Mayetiola destructor (Say)]. Plant Cell Rep. 22:150-158.

Kim, W., Johnson, J. W., Baenziger, P. S., Lukaszewski, A. J., and Gaines, C. S. 2004. Agronomic effect of wheat-rye translocation carrying rye chromatin (1R) from different sources. Crop Sci. 44:1254-1258.

Lapitan, N. L. V., Peng, J., and Sharma, V. 2007. A high-density map and PCR markers for Russian wheat aphid resistance gene Dn7 on chromosome 1RS/ 1BL. Crop Sci. 47:811-818.

Lee, T. G., Kim, D. Y., Johnson, J. W., and Seo, Y. W. 2013. A genome-wide analysis of transcripts in a 2BS.2RL wheat-rye translocation during Hessian fly infestation. Genes Genomics 35:795-803.

Lelley, T., Eder, C., and Grausgruber, H. 2004. Influence of 1BL.1RS wheatrye chromosome translocation on genotype by environment interaction. J. Cereal Sci. 39:313-320.

Li, J., Endo, T. R., Saito, M., Ishikawa, G., Nakamura, T., and Nasuda, S. 2013. Homoeologous relationship of rye chromosome arms as detected with wheat PLUG markers. Chromosoma 122:555-564.

Li, X., Xiang, Z. P., Chen, W. Q., Huang, Q. L., Liu, T. G., Li, Q., Zhong, S. F., Zhang, M., Guo, J. W., Lei, L., and Luo, P. G. 2017. Reevaluation of two quantitative trait loci for type II resistance to Fusarium head blight in wheat germplasm PI 672538. Phytopathology 107:92-99.

Lukaszewski, A. J., and Gustafson, J. P. 1983. Translocations and modifications of chromosomes in tritcale $\times$ wheat hybrids. Theor. Appl. Genet. 64: 239-248.

Mago, R., Miah, H., Lawrence, G. J., Wellings, C. R., Spielmeyer, W., Bariana, H. S., McIntosh, R. A., Pryor, A. J., and Ellis, J. G. 2005. Highresolution mapping and mutation analysis separate the rust resistance genes Sr31, $\operatorname{Lr} 26$ and $\operatorname{Yr} 9$ on the short arm of rye chromosome 1. Theor. Appl. Genet. 112:41-50.

Marais, G. F., and Marais, A. S. 1994. The derivation of compensating translocations involving homoeologous group 3 chromosomes of wheat and rye. Euphytica 79:75-80.

Mater, Y., Baenziger, S., Gill, K., Graybosch, R., Whitcher, L., Baker, C., Specht, J., and Dweikat, I. 2004. Linkage mapping of powdery mildew and greenbug resistance genes on recombinant 1RS from 'Amigo' and 'Kavkaz' wheat-rye translocations of chromosome 1RS.1AL. Genome 47: 292-298.

Molnár-Láng, M., Cseh, A., Szakács, É., and Molnár, I. 2010. Development of a wheat genotype combining the recessive crossability alleles $k r 1 k r 1 k r 2 k r 2$ and the 1BL.1RS translocation, for the rapid enrichment of 1RS with new allelic variation. Theor. Appl. Genet. 120:1535-1545.

Molnár-Láng, M., Molnár, I., Szakács, E., Linc, G., and Bedö, Z. 2014. Production and molecular cytogenetic identification of wheat-alien hybrids and introgression lines. Pages 255-283 in: Genomics of Plant Genetic Resources. T. Roberto, G. Andreas, and F. Emile, eds. Springer Science+ Business Media, Dordrecht, the Netherlands.

Qi, L. L., Friebe, B., Zhang, P., and Gill, B. S. 2007. Homoeologous recombination, chromosome engineering and crop improvement. Chromosome Res. 15:3-19.

Rabinovich, S. V. 1998. Importance of wheat-rye translocations for breeding modern cultivars of Triticum aestivum L. Euphytica 100:323-340.

Rahmatov, M., Rouse, M. N., Nirmala, J., Danilova, T., Friebe, B., Steffenson, B. J., and Johansson, E. 2016. A new 2DS·2RL Robertsonian translocation transfers stem rust resistance gene Sr59 into wheat. Theor. Appl. Genet. 129:1383-1392.

Ren, T. H., Chen, F., Yan, B. J., Zhang, H. Q., and Ren, Z. L. 2012. Genetic diversity of wheat-rye 1BL.1RS translocation lines derived from different wheat and rye sources. Euphytica 183:133-146.

Ren, T. H., Ren, Z. L., Yang, M. Y., Yan, B. J., Tan, F. Q., Fu, S. L., Tang, Z. X., and Li, Z. 2018. Novel source of 1RS from Baili rye conferred high resistance to diseases and enhanced yield traits to common wheat. Mol. Breed. 38:101.

Ren, T. H., Tang, Z. X., Fu, S. L., Yan, B. J., Tan, F. Q., Ren, Z. L., and Li, Z. 2017. Molecular cytogenetic characterization of novel wheat-rye T1RS.1BL translocation lines with high resistance to diseases and great agronomic traits. Front. Plant Sci. 8:799.

Ren, T. H., Yang, Z. J., Yan, B. J., Zhang, H. Q., Fu, S. L., and Ren, Z. L. 2009. Development and characterization of a new 1BL.1RS translocation line with resistance to stripe rust and powdery mildew of wheat. Euphytica 169: 207-213.

Ren, Z. L., Lelley, T., and Robbelen, G. 1990. The use of monosomic rye addition lines for transferring rye chromatin into bread wheat. I. The occurrence of translocations. Plant Breed. 105:257-264.

Riley, R., Capman, V., and Johnson, R. 1968. The incorporation of alien disease resistance in wheat by genetic interference with the regulation of meiotic chromosome synapsis. Genet. Res. 12:199-219. 
Rudd, J. C., Horsley, R. D., McKendry, A. L., and Elias, E. M. 2001. Host plant resistance genes for Fusarium head blight. Crop Sci. 41: 620-627.

Schlegel, R., and Korzun, V. 1997. About the origin of 1RS.1BL wheat-rye chromosome translocations from Germany. Plant Breed. 116:537-540.

Sears, E. R. 1972. Chromosome engineering in wheat. Stadler's Genet. Symp. 4:23-28.

Singh, N. K., Shepherd, K. W., and McIntosh, R. A. 1990. Linkage mapping of genes for resistance to leaf, stem and stripe rusts and $\omega$-secalins on short arm of rye chromosome 1R. Theor. Appl. Genet. 80:609-616.

Tyrka, M., and Chelkowski, J. 2004. Enhancing the resistance of triticale by using genes from wheat and rye. J. Appl. Genet. 45:283-295.

Wan, A., Chen, X., and He, Z. 2007. Wheat stripe rust in china. Aust. J. Agric. Res. 58:605-619.
Wan, A., Zhao, Z., Chen, X., He, Z., Jin, S., Jia, Q., Yao, G., Yang, J., Wang, B., and Li, G. 2004. Wheat stripe rust epidemic and virulence of Puccinia striiformis f. sp. tritici in China in 2002. Plant Dis. 88:896-904.

Wang, J. M., Kang, Z. S., and Liu, H. Y. 2009. Genetic analysis and location of a powdery mildew resistance gene in wheat landrace Hongyoumai by SSR marker. Acta Phytopathol. Sin. 39:285-289.

Wang, Z. L., Li, L. H., He, Z. H., Duan, X. Y., Zhou, Y. L., Chen, X. M., Lillemo, M., Singh, R. P., Wang, H., and Xia, X. C. 2005. Seedling and adult plant resistance to powdery mildew in Chinese bread wheat cultivars and lines. Plant Dis. 89:457-463.

Zeller, F. J. 1981. Identification of a 4A/7R and a 7B/4R wheat-rye chromosome translocation. Theor. Appl. Genet. 59:33-37.

Zhang, H. Q., and Ren, Z. L. 1998. Inducing instability of chromosomes resulted in gene transfer between wheat and rye. Hereditas (Beijing) 20:53-55. 